\title{
A utilização da análise temática em um curso de formação continuada para professores sobre Microbiologia
}

\author{
The use of thematic analysis in a continuing education course for teachers about Microbiology \\ El uso del análisis temático en un curso de formación continua para professores sobre \\ Microbiología
}

Recebido: 21/03/2021 | Revisado: 28/03/2021 | Aceito: 29/03/2021 | Publicado: 09/04/2021

Gabriella Luciano Caetano
ORCID: https://orcid.org/0000-0003-0280-4128
Secretaria Estadual de Educação do Rio de Janeiro, Brasil
Universidade Federal do Rio de Janeiro, Brasil
E-mail: gabriella-caetano@hotmail.com
Chrystian Carletti
ORCID: https://orcid.org/0000-0002-6760-3231
E-mail: chrystian.carletti@ifrj.edu.br
Instituto Federal de Educação, Ciência e Tecnologia do Rio de Janeiro, Brasil
Gustavo Henrique Varela Saturnino Alves
ORCID: https://orcid.org/0000-0002-9100-1986
Universidade Federal Fluminense, Brasil
E-mail: guto.rique.alves@ @otmail.com
Sérgio de Souza Henrique Júnior
ORCID: https://orcid.org/0000-0002-6625-9491
E-mail: sergio.souza @ifrj.edu.br
Grazielle Rodrigues Pereira
Instituto Federal de Educação, Ciência e Tecnologia do Rio de Janeiro, Brasil
ORCID: https://orcid.org/0000-0001-5685-0205
Instituto Federal de Educação, Ciência e Tecnologia do Rio de Janeiro, Brasil
Universidade Federal do Rio de Janeiro, Brasil
E-mail: grazielle.pereira@ifrj.edu.br

\section{Resumo}

A literatura disponibiliza uma diversidade de ferramentas metodológicas para análise de dados coletados em uma pesquisa qualitativa com viés educacional. Dentre as propostas existentes encontramos o método denominado tematização ou análise temática, que tem como objetivo organizar os dados coletados da pesquisa de forma que possibilitem o melhor tratamento dos achados encontrados na pesquisa, cabe salientar que esses dados são coletados por meio de entrevistas, materiais escritos e depoimentos orais. Deste modo, a tematização é uma ferramenta que pode auxiliar a sistematização do material coletado e possibilitar ao leitor uma leitura rica e articulada. Diante disto, este artigo tem como objetivo apresentar um estudo de caso, no qual foi empregada a análise temática nos dados coletados durante a ministração de um curso de formação para professores de ciências dos anos finais do ensino fundamental, nas cidades de Três Rios e Paraíba do Sul (municípios do interior do Estado do Rio de Janeiro), cujo o tema foi "Oficina de atividades lúdicas para o ensino de Microbiologia no Ensino Fundamental". Nessa perspectiva, o trabalho mostrou que diante da complexidade de informações coletadas durante o curso de formação a tematização foi um instrumento que possibilitou uma maior reflexão e uma articulação com a teoria.

Palavras-chave: Metodologia; Educação; Tematização; Curso de formação; Pesquisa qualitativa.

\begin{abstract}
The literature provides a variety of methodological tools for analyzing data collected in a qualitative research with an educational bias. Among the existing proposals we find the method called thematization or thematic analysis, which aims to organize the data collected from the research in a way that allows the best treatment of the findings found in the research, it is worth mentioning that these data are collected through interviews, written materials and oral testimonies. In this way, thematization is a tool that can help systematize the collected material and enable the reader to have a rich and articulate reading. In view of this, this article aims to present a case study, in which thematic analysis was used in the data collected during the delivery of a training course for science teachers in the final years of elementary school, in the cities of Três Rios and Paraíba do Sul (municipalities in the interior of the State of Rio de Janeiro), whose theme was "Workshop of recreational activities for the teaching of Microbiology in Elementary
\end{abstract}


Education". In this perspective, the work showed that, given the complexity of information collected during the training course, thematization was an instrument that enabled greater reflection and articulation with the theory.

Keywords: Methodology, Education; Thematization; Graduation course; Qualitative research.

\section{Resumen}

La literatura proporciona una variedad de herramientas metodológicas para analizar los datos recopilados en una investigación cualitativa con sesgo educativo. Entre las propuestas existentes encontramos el método denominado tematización o análisis temático, el cual tiene como objetivo organizar los datos recolectados de la investigación de una manera que permita el mejor tratamiento de los hallazgos encontrados en la investigación, cabe mencionar que estos datos son recolectados a través de entrevistas, materiales escritos y testimonios orales. De esta manera, la tematización es una herramienta que puede ayudar a sistematizar el material recopilado y permitir al lector tener una lectura rica y articulada. Ante esto, este artículo tiene como objetivo presentar un estudio de caso, en el que se utilizó el análisis temático en los datos recolectados durante la impartición de un curso de formación para profesores de ciencias en los últimos años de la escuela primaria, en las ciudades de Três Rios y Paraíba. do Sul (municipios del interior del Estado de Rio de Janeiro), cuyo tema fue "Taller de actividades recreativas para la enseñanza de la Microbiología en la Educación Primaria”. En esta perspectiva, el trabajo mostró que, dada la complejidad de la información recolectada durante el curso de formación, la tematización fue un instrumento que permitió una mayor reflexión y articulación con la teoría.

Palabras clave: Metodología, Educación; Tematización; Curso de formación; Investigación cualitativa.

\section{Introdução}

A metodologia qualitativa tem um caráter investigativo, por meio dela obtemos dados descritivos coletados diretamente pelo pesquisador dando mais destaque ao procedimento aplicado do que ao próprio produto, importando-nos em mostrar a percepção dos participantes (Ludke \& André, 2013). Nesse sentido, Bogdan e Biklen (1994) nos dizem que essas pesquisas concordam com os seguintes critérios:

1. Na investigação qualitativa a fonte direta de dados é o ambiente natural, constituindo o investigador o instrumento principal.

2. A investigação qualitativa é descritiva. Os dados recolhidos são em forma de palavras ou imagens e não de números.

3. Os investigadores qualitativos interessam-se mais pelo processo do que simplesmente pelos resultados ou produtos.

4. Os investigadores qualitativos tendem a analisar os seus dados de forma indutiva.

5. O significado é de importância vital na abordagem qualitativa.

Nessa perspectiva, Fontoura (2011), em seu trabalho, menciona acerca do progresso da pesquisa qualitativa na educação, a qual o conhecimento apresentado possui “olhares múltiplos e utiliza uma reflexão crítica” (Fontoura, 2011, p.62). Assim, a autora propõe a Tematização, como instrumento de análise de dados obtidos em pesquisas qualitativas.

A tematização é definida por Figueira e Fontoura (2018, p.4) como "uma técnica de identificação dos núcleos de sentido que compõe a comunicação, a partir da organização das informações coletadas, articulada com uma fundamentação teórica bem estruturada".

No mais, existem passos a serem seguidos para a organização dos dados coletados, segundo a autora Fontoura (2011, p.71-72):

1. Organização: transcrição dos dados brutos da pesquisa contidos em meio digital, em gravações audiovisuais ou de áudio, ou analógico, dados de perguntas abertas de questionários ou diários de campo, para uso e análise pelo pesquisador;

2. Revisitação: leitura minuciosa de todo o material coletado e organizado pelo pesquisador até que se exprima todos os significados pertinentes das colocações da amostra;

3. Destaque: recorte das passagens mais significantes - aos-olhos do pesquisador - das respostas da amostra, sem descontextualização ou tendêncialismo; 
4. Categorização: etapa de estratificação dos recortes da etapa de destaque em unidades que sejam coerentes, similares, pertinentes, exaustivas e exclusivas a e dentro de uma única categoria;

5. Significação: etapa de definição das unidades de contexto (transcrições longas) e unidades de significado (palavras ou expressões) que denotam os núcleos de sentido que compõem a comunicação e cuja frequência de aparição pode significar alguma coisa para o objetivo analítico escolhido;

6. Iluminação: organização das unidades (de contexto ou significado) com indicação do escólio do pesquisador a fim de apresentar um panorama geral do encaminhamento da análise dos dados;

7. Interpretação: explanação dos elementos da etapa de iluminação a partir do referencial teórico escolhido.

Ademais, a autora (ibid, 2011) ainda discorre que

A partir das interpretações, o pesquisador pode propor inferências de acordo com premissas previstas no seu quadro teórico ou abrir outras pistas em torno de dimensões teóricas sugeridas pela leitura do material. Trata-se de um longo trabalho de construção e reconstrução contínua. A análise dessa forma se caracteriza como uma reconstrução intencional e deliberada a partir do olhar do pesquisador somada aos olhares teóricos utilizados como base da investigação, que se multiplica à medida que vão se descortinando as interpretações e os caminhos conclusivos (Fontoura, 2011, p. 73).

Em face do exposto, a técnica de tematização pode ser uma metodologia aplicada em pesquisas qualitativas que envolvam coleta de dados por meio de entrevistas, materiais escritos e depoimentos orais.

Diante do exposto o trabalho, aqui apresentado, trata-se de um curso de formação continuada para docentes de ciências dos anos finais do ensino fundamental tendo como temática os organismos procariontes. Cabe mencionar que os cursos de formação continuada colaboram para a inserção de novas metodologias na sala de aula e gerar discussões científicas atuais (Moresco et. al., 2017).

Ainda nessa perspectiva sobre curso de formação continuada a autora Jacobucci (2006), menciona que os cursos podem complementar a lacuna da formação inicial além de contribuir para a inserção de novas metodologias de ensino. Veloso e Sobrinho (2017) dissertam que os cursos de formação continuada para professores são:

os diversos processos que possibilitam o aprofundamento e a construção de novos conhecimentos pelo docente, por meio de palestras, seminários, cursos e oficinas sistematizadas, de modo a intencionar a melhoria das práticas pedagógicas e a formação de indivíduos críticos e reflexivos (p. 311).

Com isso, esses ambientes são propícios a reflexão do docente de forma crítica uma vez que, o profissional irá analisar seu local de trabalho e sua atuação compreendendo seu papel na formação do discente (Contreras, 2012), como também, segundo Pereira et al. (2017), a formação continuada pode propiciar e fomentar um espaço de debate que busca estabelecer "a troca de vivências pedagógicas e experiências, além de reflexões a respeito das questões sociais e políticas que perpassam a educação" (p. 19). Segundo os autores (Pereira, et al. 2017) o ato de ouvir a si mesmo e aos outros durante os debates propiciados na formação de professores tende a ser um elemento de reflexão sobre suas próprias concepções a respeito da educação científica e o contexto escolar.

Com relação a temática trabalhada no curso de formação, as autoras Jacobucci e Jacobucci (2009) discorrem sobre a importância de os alunos conhecerem sobre os microrganismos de forma ampla, uma vez que a mídia, geralmente, associa a temática apenas com as doenças que esses microrganismos podem transmitir (Barbosa e De Oliveira, 2015). Sendo, dessa forma, importante a discussão desse conteúdo na sala de aula para a construção de uma aprendizagem significativa (Azevedo e Sodre, 2014).

Dessa forma, e devido ao tempo de execução do curso de formação foi trabalhado junto aos docentes especificamente sobre os organismos procariontes, as bactérias e arqueobactérias. Cuja a temática segundo os autores Moresco et al (2017) e 
Medeiros et. al (2018) e Caetano e Pereira (2017) os docentes possuem barreiras no ensino de microrganismos, uma vez que as escolas não possuem, em sua maioria, recursos disponíveis e adequados para a visualização desses microrganismos e podendo, dessa forma, ser negligenciado pelos docentes por causa da escassez de estratégias de ensino.

Os organismos procariontes ou procarióticos, possuem como principais características:

1. Seu DNA não está envolvido por uma membrana, e ele é um cromossomo de arranjo circular.

2. Seu DNA não está associado com histonas (proteínas cromossômicas especiais encontradas em eucariotos); outras proteínas estão associadas ao DNA.

3. Eles não possuem organelas revestidas por membrana.

4. Suas paredes celulares quase sempre contêm o polissacarídeo complexo peptideoglicano.

5. Eles normalmente se dividem por fissão binária. Durante esse processo, o DNA é duplicado e a célula se divide em duas. A fissão envolve menos estruturas e processos que a divisão das células eucarióticas (Tortora et al., 2016, p. 77).

O termo procarioto, tem origem grega e significa pré-núcleo uma vez que, esses organismos não possuem um núcleo delimitado como os organismos eucariontes, assim o material genético encontra-se disperso no citoplasma (Tortora et. al, 2016).

Em face do exposto, a presente pesquisa, tem como objetivo utilizar a tematização para analisar os dados coletados em um curso de formação para professores de ciências dos anos finais do ensino fundamental aplicados nos municípios de Três Rios e Paraíba do Sul.

\section{Metodologia}

Esta pesquisa possui caráter exploratório sendo caracterizada pelo protagonismo nas percepções dos participantes, sendo pautada, dessa forma, em uma metodologia qualitativa (Lüdke, \& André, 2013). O autor Minayo (2013) discorre que nas pesquisas qualitativas as interpretações dos fenômenos e a atribuição de significados são o pilar do processo investigativo. Além disso, pesquisas qualitativas segundo os autores Matins e Theófilo (2009), precisam de muita atenção uma vez que investigações qualitativas se dedicam a observação do comportamento dos pesquisados e busca compreender a pluralidade do objeto de estudo nas situações sugeridas.

Diante disso, o curso de formação aqui apresentado foi idealizado para professores de Ciências dos anos finais do ensino fundamental, sendo desenvolvido com o objetivo de apresentar às docentes ferramentas pedagógicas para o ensino sobre bactérias e arqueobactérias, além de propiciar a troca de experiências e reflexões acerca da docência.

Assim sendo, o curso foi aplicado em forma de oficina tendo como título "Oficina de atividades lúdicas para o ensino de Microbiologia no Ensino Fundamental”. As oficinas foram realizadas em Três Rios, na Escola Municipal Américo Silva, em 30 de outubro e 13 de novembro de 2018, e na cidade de Paraíba do Sul, na sede da Secretaria Municipal de Educação, nos dias 21 e 27 de novembro de 2018, ambas com uma carga horária de 4 horas.

Com relação a coleta de dados, aplicou-se um questionário misto (perguntas abertas e fechadas) a todos os participantes o qual foi preenchido por eles e após a aplicação do questionário realizou-se o grupo de discussão, o qual propicia a troca de experiências e reflexões dos participantes, os dados desta etapa foram colhidos por meio de imagem, áudio e vídeo.

Para analisar o material coletado segundo a análise temática de Fontoura (2011), realizou-se a transcrição dos questionários, vídeos e gravações, leitura atenta, marcação e delimitação do texto para a construção dos temas e as definições das unidades de contexto e unidades de significado.

Desta forma, os dados coletados foram elaborados em um quadro com duas colunas, Categorias e Unidade de contexto, para que a análise pudesse ser realizada de forma mais abrangente, como sugere Fontoura (2011).

Vale esclarecer que unidades de contexto são os trechos longos, ou seja, as falas dos participantes, e tem como função 
evidenciar o tema; já as unidades de significado são palavras ou expressões essenciais das falas dos participantes, na categoria em questão.

Por fim, para a apresentação do conteúdo da transcrição e identificação dos 12 participantes da pesquisa, foi utilizada a letra P e um número de 1 a 12 (P1, P2, P3... P12). Este estudo foi apresentado às Secretarias Municipais de Três Rios e Paraíba do Sul e, em concordância, foi avaliada pelo Comitê de Ética em Pesquisa, do Hospital Universitário Clementino Fraga Filho, obtendo o CAAE de 91725818.8.0000.5257, por meio do parecer 2.839.550. A coleta de dados foi amparada pelo Termo de Consentimento Livre e Esclarecido acordado entre os pesquisadores e os entrevistados.

\section{Resultados e Discussão}

Por meio do questionário misto e do grupo de discussão foi possível abordar importantes conceitos de microbiologia relacionados aos procariontes como: saúde, ambiente e economia.

Ademais, foi possível validar uma ferramenta diversificada junto aos docentes participantes dessa pesquisa, o jogo didático "Procarionte Profile", um jogo de tabuleiro, que tem como objetivo auxiliar o docente no ensino sobre bactérias e arqueobactérias estimulando os discentes de forma atrativa a aprenderem sobre a complexidade dos procariontes (Caetano e Pereira, 2020).

Analisando o material coletado e seguindo os princípios estabelecidos por Fontoura (2011) de correlação, paridade, relevância, detalhamento e especificidade, foram criados os seguintes temas:1. A relação do professor com o ensino acerca dos procariontes; 2. O ensino sobre bacterioses e 3. A ausência de recursos na escola. Em cada tema, é apresentado um quadro com depoimentos dos participantes (unidades de contexto) que retratam a investigação da entrevista.

Por último, segundo a proposta da autora (ibid, 2011) os dados a serem tratados podem ser transcritos em quadros, para que o pesquisador tenha um panorama amplo da condução da análise de seus dados, desta forma estes dados serão apresentados de acordo com a sugestão da autora.

\subsection{A relação do professor com o ensino acerca dos procariontes}

Com relação ao ensino sobre os procariontes, realizados pelos docentes, foram identificadas três categorias: a maturidade dos alunos para o tema, a exploração dos livros didáticos e a transmissão conteudista (Quadro 1). 
Quadro 1. Categorias do tema "A relação do professor com o ensino acerca dos procariontes".

\begin{tabular}{|c|c|}
\hline Categorias & Unidades de contexto \\
\hline A maturidade dos alunos & $\begin{array}{l}\text { "O Ensino Fundamental, não tem maturidade". } \\
\text { (Docente P1, } 56 \text { anos) } \\
\text { "E eles não tem muita maturidade pra entender a } \\
\text { importância desses seres vivos". (Docente P2, } 49 \\
\text { anos) } \\
\text { "eles não têm maturidade para aprender". } \\
\text { (Docente P3, } 48 \text { anos) } \\
\text { "No ensino fundamental eles são muito crianças } \\
\text { ainda são muito imaturos". (Docente P4, } 58 \text { anos) }\end{array}$ \\
\hline Exploração dos livros & $\begin{array}{l}\text { "Eu trabalho utilizando os livros, mas tem poucas } \\
\text { imagens pra eu entender (no caso o aluno)", "os } \\
\text { livros do ensino fundamental requer mencionar as } \\
\text { arqueobactérias" (Docente P2, } 49 \text { anos) } \\
\text { "Utilizo muito o livro didático e ele fica na } \\
\text { escola, aí o aluno usa e ele volta a ser guardado". } \\
\text { (Docente P4, } 58 \text { anos) } \\
\text { "Eu utilizo muito o livro". (Docente P5, } 29 \text { anos) } \\
\text { "Nossa usamos muito o livro didático". (Docente } \\
\text { P6, } 46 \text { anos) }\end{array}$ \\
\hline A transmissão do conteúdo & $\begin{array}{l}\text { "No ensino fundamental é o básico mesmo, você } \\
\text { fala como elas se reproduzem, algumas doenças e } \\
\text { nada mais". (Docente, P4 } 58 \text { anos) } \\
\text { "mais teorias, ou melhor só teorias". (Docente P1, } \\
56 \text { anos) } \\
\text { "conceitos básicos sobre as bactérias e } \\
\text { arqueobactérias". (Docente P2, } 49 \text { anos) } \\
\text { "somente a parte teórica, bem superficial". } \\
\text { (Docente P7, } 42 \text { anos) }\end{array}$ \\
\hline
\end{tabular}

Fonte: Autores.

Após a análise dos dados da pesquisa, verificou-se que grande parte dos docentes, ao trabalharem o tema procariontes com seus alunos, lamentam sobre a postura dos alunos frente ao tema; denominando-os como imaturos. De acordo com a estrutura dos PCN

o $3^{\circ}$ ciclo abrange $6^{\circ}$ ano e $7^{\circ}$ ano dos anos finais do ensino fundamental o documento o aluno vive a juventude podendo ampliar a participação em seu meio social e desenvolvendo uma atitude crítica que dirige tanto as relações pessoais como a outros aspectos de sua vida cultural e afetiva... o professor de ciências naturais precisam abrir diálogo, encontrar respostas e incentivo adequados para o amadurecimento crítico de seus alunos (Brasil, 1998, p.57).

Desta forma é importante que o professor, ao planejar suas aulas acerca dos procariontes, leve em consideração a que fase de amadurecimento seu aluno se encontra, para que possa despertar o aluno para o conhecimento do tema e possam ter uma "aprendizagem significativa" (Azevedo \& Sodré, 2014).

Com relação aos livros didáticos (LD) pode-se exemplificar a função atribuída pelas docentes com o seguinte depoimento 
“trabalho usando os livros, mas tem poucas imagens para eu entender (no caso o aluno) o que é uma bactéria, a reprodução e como isso os alunos não tem a oportunidade de conhecer a importância...falta nos livros a importância da microbiologia." (Docente P2, 49 anos)

Essa concepção corrobora para os resultados encontrados no trabalho Silva e Bastos (2012), no qual os professores de Ciências entrevistados alegaram que a falta de material nas escolas consiste na principal dificuldade no ensino do tema.

Além disso, Conceição et. al (2020) discorrem sobre a importância do acesso ao LD e sobre a fácil acessibilidade que docentes e discentes das escolas possuem, além de serem utilizados pelo professor como material de apoio para seus planejamentos de aula, porém o ensino não pode ficar restrito exclusivamente a esse material. Conforme Rosa e Santos (2013) "os alunos "clamam” por métodos inovadores de ensino-aprendizagem".

Por fim, foi observado nesta categoria que alguns participantes trabalham o tema de forma conteudista e superficial como escreveu P7 acerca do que ela consegue desenvolver com os alunos "somente a parte teórica, bem superficial".

A professora P1 registrou ainda "mais teorias, ou melhor só teorias". Esses depoimentos evidenciam o que Moresco (2017) aponta sobre a importância da compreensão sobre os microrganismos para o planeta de forma ampla, ou seja, suas contribuições para o meio ambiente, para os sistemas biológicos de nosso corpo, um ensino pautado só no teórico distância os papéis exercidos dos micróbios da realidade dos alunos. Nessa perspectiva de ensinar, Azevedo e Sodré (2014) relatam que o ensino de bacteriologia ainda é executado de forma tradicional.

\subsection{O ensino sobre bacterioses}

Com relação ao ensino das bacterioses, foram percebidas entusiasmo nas falas dos docentes associando o tema com uma categoria: a contextualização dos procariontes (Quadro 2).

Quadro 2. Categoria do tema "a contextualização dos procariontes".

\begin{tabular}{|l|c|}
\hline Categoria & Unidades de Contexto \\
\hline "a parte que eles mais se interessam é a parte de \\
quando a gente começa a falar de doenças" \\
(Docente P8, 42 anos) \\
A contextualização dos procariontes \\
"as doenças é o tema que tem mais interesse, \\
porque ai é o dia a dia". (P7, 42 anos) \\
"eu trabalho mais geralmente as partes de \\
doenças". (Docente P3, 48 anos) \\
"Trabalho mais com a parte de doenças". (Docente, \\
, P4, 58 anos)
\end{tabular}

Fonte: Autores.

$\mathrm{Na}$ categoria “A contextualização dos procariontes", foi observado ao longo dos depoimentos, que a parte dos procariontes que os pesquisados possuem mais interesse é as bacterioses, já que os mesmos conseguem associar o conteúdo com o seu cotidiano, como expõe P7 “as doenças é o tema que tem mais interesse, porque aí é o dia a dia”.

Falas como essa se repetiram durante a discussão, é importante salientar que, ao se trabalhar esse tema com os alunos, os professores elucidem que apenas $2 \%$ das bactérias são patogênicas, ou seja, $98 \%$ delas realizam inúmeras funções que não 
estão associadas a transmissão de doenças (Cassanti et al, 2007). É importante que os professores saibam a importância de ensinar bacteriologia e de desconstruírem a ideia de que bactérias estão relacionadas estritamente a efeitos negativos (Azevedo e Sodré, 2014).

O autor Azevedo (2014) aponta que a bacteriologia é uma área que possibilita diversas relações de conteúdo com o dia a dia, e esta possibilidade tende a despertar o interesse do aluno. Segundo Silva e Bastos (2012) é relevante mostrar aos alunos a diversidade de ambiente que as bactérias estão presentes, evidenciando também seus diversos benefícios, uma vez que um aluno com esse olhar amplo sobre os procariontes será um cidadão crítico quanto ao papel dos seres vivos no ambiente (Toledo, 2015).

\subsection{A ausência de recursos na escola}

Com relação a ausência de recursos na escola, foi observado duas categorias: a inserção de um laboratório e a necessidade de ferramentas para a abordagem do conteúdo (Quadro 3).

Quadro 3. Categorias do tema "Ausência de recursos na escola".

\begin{tabular}{|c|c|}
\hline Categoria & Unidades de contexto \\
\hline A inserção de um laboratório & $\begin{array}{c}\text { “Não tem microscópio, não tem laboratório”. } \\
\text { (Docente P2, } 49 \text { anos) } \\
\text { "Na minha escola tem laboratório, mas os alunos } \\
\text { do ensino fundamental não podem usar" (Docente } \\
\text { P1, } 56 \text { anos) } \\
\text { "É necessário de início ter um microscópio, seria } \\
\text { o básico". (Docente, P4, } 58 \text { anos) } \\
\text { “Ter um laboratório, porque é necessário, sinto } \\
\text { falta das aulas práticas”. (Docente P6, } 46 \text { anos) } \\
\text { "Atividades práticas uso de laboratórios”. } \\
\text { (Docente P8, } 42 \text { anos) } \\
\text { “Aulas práticas, microscopia". (Docente P9, } 55 \\
\text { anos) }\end{array}$ \\
\hline $\begin{array}{l}\text { Necessidade de Ferramentas para a abordagem do } \\
\text { conteúdo }\end{array}$ & $\begin{array}{c}\text { "É preciso ter meios tecnológicos, como } \\
\text { Datashow para visualização das estruturas } \\
\text { bacterianas". (Docente P5, } 29 \text { anos) } \\
\text { "Tornar menos chato, é teórico demais"; "Eu se } \\
\text { tivesse uma televisão para mim já estava de bom } \\
\text { tamanho". (Docente, P3,48 anos) } \\
\text { "Na minha escola nem Datashow tem". (Docente, } \\
\text { P7, } 42 \text { anos) }\end{array}$ \\
\hline
\end{tabular}

Fonte: Autores.

O microscópio é fundamental para a observação bacteriana, já que são seres vivos minúsculos, sendo impossível sua observação a olho nu. Na graduação, as aulas em laboratórios fazem parte da grade curricular permitindo que o graduando em Ciências Biológicas, possa ter contato com o mundo microscópico dos seres vivos de forma direta. Porém, essa realidade não é de todos os alunos da educação básica brasileira, muita das vezes esses só têm contato com as bactérias e arqueas através das imagens que os livros didáticos possuem e da construção de imagens vindas das falas, desenhos dos professores sobre esses microrganismos.

Notou-se com as falas a importância que as docentes empregam ao microscópio para o processo de ensino e aprendizagem sobre microrganismos. Porém, sabe-se que apenas o instrumento não sanaria as necessidades das docentes para ministrarem aulas acerca dos microrganismos procariontes, já que esse instrumento necessita de todo um aparato para ser 
utilizado, aparatos esses que também não possuem nas escolas pesquisadas, por exemplo, uma televisão para que as imagens obtidas no microscópio sejam projetadas nela, além das amostras bacterianas para serem analisadas no microscópio.

Dessa forma, se faz necessário um planejamento de aulas diversificadas, considerando os elementos que podem facilitar o processo de ensino e aprendizagem levando em conta também a realidade que cada escola possui (Toledo et al., 2015).

Acerca da categoria Necessidade de Ferramentas para a abordagem do conteúdo, notou-se a que as escolas não possuem televisão, retroprojetores e conexão com internet estável e que isto poderia auxiliar os docentes no processo de ensino sobre os microrganismos. De acordo com uma professora:

"É preciso ter meios tecnológicos, como Datashow para visualização das estruturas bacterianas". (Docente P5, 29 anos)

Sabemos que para a abordagem de alguns temas da Ciências se faz necessário o uso de algumas ferramentas, para que, além de complementar as informações contidas nos manuais, tornem as aulas mais atrativas e menos teóricas, assim é importante que o docente conheça sua realidade escolar e a partir daí trace estratégias de ensino, corroborando com o que o autor Martignago (2017) pontua em seu trabalho sobre a necessidade de planejamento de atividades para que as mesmas alcancem os alunos de forma eficaz.

\section{Considerações Finais}

As pesquisas de cunho qualitativo, são metodologias que contribuem para um olhar mais amplo e reflexivo acerca do conhecimento apresentado, possibilitando uma grande coleta de dados a serem tratados. Nesse sentido, a técnica da tematização é um viés muito interessante para este tratamento, uma vez que essa técnica permite organizar os dados de forma clara e objetiva para o leitor, mas não perdendo a sua singularidade e a fala do participante da pesquisa, o qual foi interpretado ao longo de todo processo.

Dessa maneira, podemos inferir que a técnica da tematização nos possibilitou analisar os depoimentos e narrativas dos professores de ciências acerca de suas diferentes realidades sobre o ensino de microbiologia (por exemplo, a "necessidade de ferramentas para a abordagem do conteúdo"; "ausência de laboratórios" ou mesmo "a imaturidade dos alunos"), descortinado questões inerentes ao ensino de ciências no contexto do ensino fundamental nos municípios de Três Rios e Paraíba do Sul. Tais dados foram importantes para a construção coletiva (pesquisadores e professores participantes da pesquisa) de materiais de apoio para o ensino de microbiologia.

Importante destacar que essa proposta metodológica não é fechada, tendo em vista que o pesquisador irá decidir como trabalhar as informações coletadas e realizar adaptações, de acordo com os dados obtidos e a escolha do referencial teórico.

Por fim, o curso de formação ministrado aos docentes participantes desta pesquisa foi disponibilizado em forma de cartilha na plataforma EduCAPES, para que mais docentes possam ter contato com a proposta, e assim inserir novas ferramentas de ensino em suas aulas. Além de fomentar a discussão acerca de curso de formação para docentes e microrganismos, uma vez que esses organismos por serem microscópicos necessitam de um olhar atento por parte do docente ao ensinar a seus alunos.

\section{Agradecimentos}

Agradecemos as secretarias de Educação dos municípios de Três Rios e Paraíba do Sul, pela parceria e acolhimento ao longo do desenvolvimento do curso de formação. Aos docentes participantes, que prontamente aceitaram participar e 
Research, Society and Development, v. 10, n. 4, e24210414109, 2021

(CC BY 4.0) | ISSN 2525-3409 | DOI: http://dx.doi.org/10.33448/rsd-v10i4.14109

fizeram do ambiente um local de troca de experiências, sem vocês essa pesquisa não poderia ter ocorrido.

\section{Referências}

Azevedo, T., \& Sodré, L. (2014). Bacteriologia na Educação Básica: como este tema é abordado nos livros didáticos? Acta Scientiae, 16(3).

Barbosa, F. G., \& de Oliveira, N. C. (2015). Estratégias para o Ensino de Microbiologia: uma Experiência com Alunos do Ensino Fundamental em uma Escola de Anápolis-GO. Revista de Ensino, Educação e Ciências Humanas, 16(1), 5-13.

Bogdan, R.; Biklen, S. Investigação qualitativa em educação: uma introdução à teoria e aos métodos. Porto Editora, 1994.

Brasil. Parâmetros Curriculares Nacionais (1998). Terceiro e quarto ciclos do Ensino Fundamental. MEC-Secretaria de Educação Fundamental.

Caetano, G. L. O ensino dos domínios bactéria e archaea nos anos finais do ensino fundamental e a proposição de um jogo acerca desses domínios (2017). Dissertação (Mestrado em Educação, Gestão e Difusão em Biociências) - Universidade Federal do Rio de Janeiro.

Caetano, G. L., \& Pereira, G. R. (2020). Proposição de um jogo didático acerca dos procariontes para os anos finais do Ensino Fundamental. Research, Society and Development, 9 (9), e348997373-e348997373.

Cândido, M. D. S. C., Santos, M. G., de Medeiros Azevedo, T., \& Neto, L. S. (2015). Microbiologia no ensino médio: analisando a realidade e sugerindo alternativas de ensino numa escola estadual Paraibana. Ensino, Saúde e Ambiente, 8(1).

Cassanti, A. C., Cassanti, A. C., Araujo, E. D., \& Ursi, S. (2008). Microbiologia democrática: estratégias de ensino-aprendizagem e formação de professores. Revista Conhecer, 9(1), 84-93.

Conceição, D. D. S. S., Braga, J. R. M., \& dos Santos Protázio, A. (2020). Análise do conteúdo "animais peçonhentos" nos livros didáticos de Ciências Naturais. EDUCA-Revista Multidisciplinar em Educação, 7(17), 1357-1381.

Contreras, J. (2002). A autonomia de professores. Cortez.

Figueira, S. T. S, \& da Fontoura, H. A. (2018). Ensinar e aprender ciências: o que dizem professores? Revista Areté| Revista Amazônica de Ensino de Ciências, 11(23), 55-62.

Fontoura, H. D. (2011). Tematização como proposta de análise de dados na pesquisa qualitativa. Formação de professores e diversidades culturais: múltiplos olhares em pesquisa. Niterói: Intertexto, 1, 61-82.

Jacobucci, D. F. C., \& Jacobucci, G. B. (2009). Abrindo o Tubo de Ensaio: o que sabemos sobre as pesquisas em Divulgação Científica e Ensino de Microbiologia no Brasil. JCOM, 8(2), 1-8.

Jacobucci, D. F. C. (2006). A formação continuada de professores em centros e museus de ciências no Brasil.

Ludke, M., \& André, M. (2013). Pesquisa em educação: abordagens qualitativas. (EPU, Ed.), Pesquisa em educação: abordagens qualitativas (2nd ed.).

Martignago, D. C. (2017). Aplicação de um jogo como facilitador na aprendizagem de estudantes do ensino médio sobre evolução biológica.

Martins, G. D. A., \& Theóphilo, C. R. (2009). Metodologia da investigação cientifica. Atlas, 143-164.

Medeiros, L. P. et al. Reconhecendo a Microbiologia no nosso dia a dia pelo método PBL por estudantes do ensino médio. Luminária, 19(01).

Minayo, M. C. D. S. (2012). Análise qualitativa: teoria, passos e fidedignidade. Ciência \& saúde coletiva, 17, $621-626$.

Moresco, T. R., Carvalho, M. S., Klein, V., Lima, A. D. S., Barbosa, N. V., \& Rocha, J. D. (2017). Ensino de microbiologia ex perimental para Educação Básica no contexto da formação continuada. Revista Electrónica de Enseñanza de las Ciencias, 16(3), 435-457.

Pereira, G. R. et al. Formação continuada de professores dos anos iniciais da educação básica: impacto do programa formativo de um museu de ciência a partir do viés crítico reflexivo (2017). Revista Ensaio. Pesquisa em Educação em Ciências. 19(e2470), 1-22.

Rosa, M. D. A., \& dos Santos, J. V. A. (2013). O uso do livro didático nas aulas de ciências: alguns apontamentos com base em textos da área. Encontro Regional de Ensino de Biologia, 5.

Silva, M., \& Bastos, S. N. D. (2012). Formação continuada de professores: o ensino da microbiologia através de recursos pedagógicos alternativos. Encontro Nacional de Ensino de Ciências da Saúde e do Ambiente, 3.

Toledo, A. G., Poersch, K. M., do Nascimento, J. E., \& de Lima, B. G. T. (2015). Estudo da microbiologia e sua relação no cotidiano do aluno a partir da temática saúde. Ensino, Saude e Ambiente, 8(2).

Tortora, G. J., Case, C. L., \& Funke, B. R. (2016). Microbiologia. (12a ed.), Artmed Editora.

Veloso, C., \& Sobrinho, J. A. D. C. M. (2017). Contribuições da formação continuada na ótica do professor de Ciências Naturais. Retratos da Escola, 11(20), 309-321. 